\title{
Fluorescência da Clorofila, Orbitais e Fotossíntese: atividades práticas integrando conceitos de Química, Física e Biologia
}

\section{Chlorophyll fluorescence, Orbital and Photosynthesis: practical activities integrating concepts of Chemistry, Physics and Biology}

\author{
Elgion Lucio da Silva Loreto ${ }^{1 *}$, Lenira Maria Nunes Sepe ${ }^{1}$
}

*email: elgionl@gmail.com

${ }^{1}$ Programa de Pós-Graduação Educação em Ciências Química da Vida e Saúde, Depto. de Biologia, Universidade Federal de Santa Maria.

\begin{abstract}
Resumo
As práticas descritas exploram a relação entre a reserva de energia realizada na fotossíntese e a emissão de fluorescência pela clorofila quando em solução em contraposição a ausência de fluorescência quando esta está presente nos cloroplastos. Poderá ser utilizada como atividade demonstrativa de curta duração ou com atividade de duração mais longa, permitindo a exploração de vários conceitos ligados à fotossíntese. Os materiais propostos para a execução das atividades são simples, o que torna possível a construção pelos alunos, possibilitando o desenvolvimento de várias habilidades e de propostas experimentais. Os protocolos são baseados em registro de observações e perguntas-chave para a continuidade da execução. As perguntas criam pausas para momentos de reflexão e revisão de conceitos durante a realização da prática. As atividades visam proporcionar elementos para o entendimento da fotossíntese como um fenômeno que necessita, para seu entendimento, aportes de diferentes disciplinas.
\end{abstract}

Palavras-chave: Fluorescência, fotossíntese, ligações químicas.

\begin{abstract}
These laboratory activities explore the relationship between the reserve of energy that occur during photosynthesis and the chlorophyll fluorescence emission when in solution as opposed to absence of fluorescence when the chlorophyll are in intact chloroplasts. This proposal can be used as short demo or as activities with longer duration, to show chlorophyll's properties associated with the photosynthesis. The materials proposed for the implementation of the activities are simple, and possible to building it by the students, enabling the development of various skills and experimental proposals. The protocols are based on observations and record key questions to continue the execution. During the activities, questions promotes pauses for moments of reflection and review of concepts. At the end are presented and discussed proposals for development of interdisciplinary projects.
\end{abstract}

Keywords: Fluorescence, photosynthesis, chemical bonds. 


\section{Ficha da atividade desenvolvida}

Título: Fluorescência, orbitais e fotossíntese.

Público alvo: alunos de graduação

Disciplinas relacionadas: Bioquímica, Biologia celular.

Objetivos educacionais: Apresentar, de forma prática, algumas propriedades físicoquímicas da clorofila objetivando que os estudantes relacionem estas propriedades com a transdução energética realizada na fotossíntese.

Justificativa de uso: Permite relacionar prática e teoria; permite desenvolver habilidades como observação, formulação e teste de hipóteses.

Conteúdos trabalhados: Fotossíntese, níveis quânticos dos orbitais eletrônicos, estados excitados dos elétrons e sua relação com a fotossíntese, fluorescência.

Link de acesso: http://w3.ufsm.br/labdros/arquivos/aula_fluoresc.pdf 


\section{Introdução}

Fotossíntese consiste em uma série de reações químicas que ocorrem nos cloroplastos e a compreensão desse processo depende da integração de conhecimentos de diferentes áreas. A complexidade da fotossíntese não permite que esta seja apresentada de modo isolado como um fenômeno biológico ou físico-químico. Este é um assunto marcadamente interdisciplinar. Conceitos essenciais da Química, Física e Biologia - por exemplo: modelo atômico, orbitais e seus níveis de energia, ligações químicas, ondas eletromagnéticas, fótons, estrutura do cloroplasto e suas membranas lipoproteicas, rotas metabólicas e suas enzimas - devem fazer parte da explicação de como as plantas utilizam a luz solar para a produção de moléculas que armazenam energia.

A atividade pode ser conduzida de modo demonstrativo ou experimental através da mudança de algumas variáveis. Na forma de atividade demonstrativa pode ser desenvolvida em uma aula típica de dois períodos e está centrada no questionamento e explicações do professor. Pode também ser aplicada de forma experimental em que as questões e atividades experimentais são desenvolvidas pelos alunos, tendo estes um papel mais ativo na busca de informações e testar hipóteses, ou mesmos em uma atividade "Hands-On" de curta duração.

A proposta tem dois momentos. No primeiro experimento é demonstrado que os cloroplastos são estruturas celulares que podem ser separadas através de centrifugação. No segundo experimento demonstra-se que i) quando os cloroplastos são desintegrados pela ação de um detergente, o pigmento clorofila fica disperso na solução; ii) a clorofila em solução, quando excitada pela luz azul, fluoresce emitindo luz vermelha; iv) a clorofila, nos cloroplastos íntegros não fluoresce. Esse conjunto de práticas cria a possibilidade de implementar a interdisciplinaridade como apontado em [1], por meio de práticas integradas ao processo de ensino aprendizagem significativos com inter-relações dos conhecimentos disciplinares com o cotidiano.

O fato da exposição de cloroplastos intactos à luz azul não resultar em fluorescência pode ser explicada devido à existência da cadeia transportadora de elétrons que capta os elétrons que "saltam" de seus orbitais quanto excitados pela luz [2] . Essa situação pode ser usada para discutir vários conceitos associados ao processo de fotossíntese. $\mathrm{O}$ conjunto de práticas deve desenvolver-se por meio de questionamentos e 
proposição de hipóteses explicativas decorrentes do que foi observado. Ao final de cada etapa, é possível detectar as principais dificuldades dos alunos em relação aos conceitos necessários para explicação dos fenômenos observados e, assim, na medida em que for necessário, o professor poderá complementar com informações adicionais auxiliando a turma no entendimento do fenômeno, no caso de atividade demonstrativa. No caso de atividade experimental de maior duração, estas dificuldades e questionamentos podem ser fonte de busca ativa de informação bibliográfica ou de ensaios experimentais idealizados pelos alunos, com orientação do professor. A descrição abaixo está centrada preponderantemente em uma aula experimental demonstrativa, com grande apoio do professor. Um roteiro de aula prática Hand-On de curta duração, com pouca intervenção do professor, pode ser encontrado em http://w3.ufsm.br/labdros/arquivos/aula_fluoresc.pdf

\section{Material}

\subsection{Equipamentos}

Gral, pistilo ou outro material que possa ser usado para esmagar folhas (ex.: pires e colher); Pipeta Pasteur ou uma seringa descartável ( $3 \mathrm{~mL}$ ); Centrífuga e tubos de microcentrífuga (Figura 1 A); LED azul e acrílico vermelho (Figura 1 B). Para mais detalhes de como construir uma centrífuga consulte [3] e o sobre como ligar um LED consulte [4].

\subsection{Reagentes}

Água, detergente de cozinha.

\subsection{Amostras biológicas}

Sugerimos empregar folhas Tradescantia pallida purpurea, também conhecida como "manto-de-viúva" (Figura 2A). Essa planta tem as folhas roxas devido à presença do pigmento antocianina que permitirá observar melhor o processo da centrifugação. Porém, outras espécies com folhas fáceis de macerar podem ser usadas, por exemplo, alface ou espinafre. 
Fluorescência da Clorofila, Orbitais e Fotossíntese: atividades práticas integrando conceitos de Química, Física e Biologia

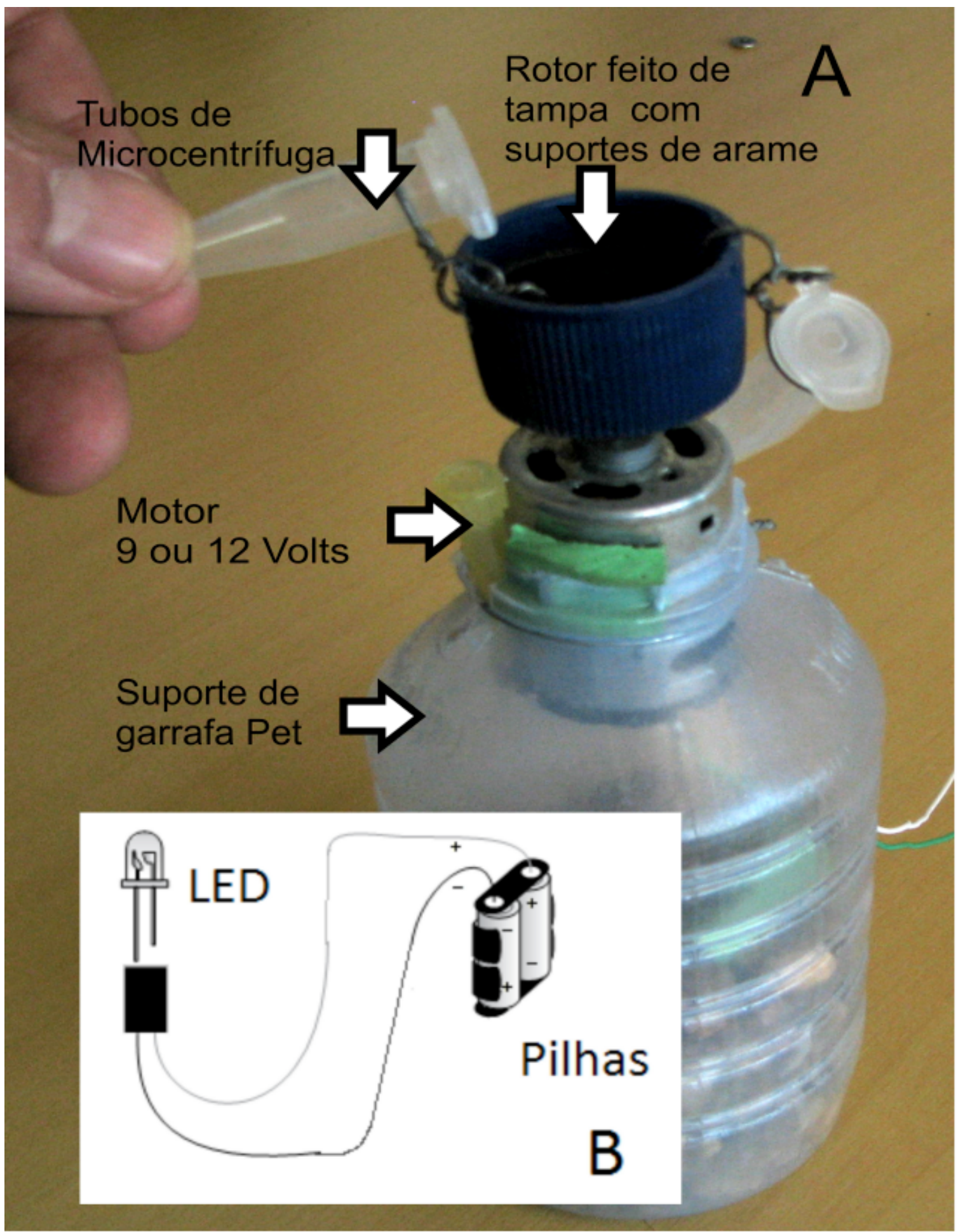

Figura 1. A- Centrífuga construída com um motor de 9 ou 12 volts que (pode ser obtido em brinquedos, secador de cabelo ou qualquer outro tipo de equipamento pequeno movido a pilha); rotor foi feito de tampa de garrafa PET e fixado ao eixo do motor com cola epóxi; o motor é fixado a uma garrafa PET preenchida com material pesado (ex: pedrinhas) para dar estabilidade ao sistema, o motor pode ser acionado com pilhas ou um carregador de celular. Os tubos de microcentrífuga são acondicionados em uma estrutura de arame que muda de ângulo para horizontal quando o motor é acionado. A baixa voltagem e rotação do motor, tornam o equipamento seguro para ser empregado em sala de aula. B- O sistema de iluminação para fluorescência é feito com um LED de alto-brilho, azul ou violeta, que pode ser adquirido em lojas de material eletrônico. O LED deve ser ligado a duas pilhas de 1,5 V. Mais informações em [4]. 


\section{Procedimento}

\subsection{Experimento 1}

1 - Em um gral coloque duas folhas e $3 \mathrm{~mL}$ de água. Com um pistilo macere as folhas até obter um líquido bem escuro (homogeneizado).

Questionamentos: O que está ocorrendo com o material durante esse procedimento? Os tecidos vegetais são comprimidos, muitas células se rompem e seu conteúdo extravasará para o líquido.

2 - Com uma pipeta Pasteur, transfira $1 \mathrm{~mL}$ do homogeneizado para um tubo de microcentrífuga de $1,5 \mathrm{~mL}$. Centrifugue por 1 minuto.

Importante: Os tubos devem ser balanceados para a centrifugação, ou seja, os tubos que estão em posições opostas do rotor precisam ter o mesmo volume de líquido.

Questionamentos: Como funciona a centrífuga? Explicar o funcionamento da centrífuga é uma boa oportunidade para desenvolver observações sobre segurança na utilização de equipamentos e para uma apresentação ou revisão rápida sobre a importância da centrifugação como método de separação de diferentes fases de uma solução, principalmente quando esta consistir de uma fase "sólida" e uma aquosa. A construção da centrífuga é uma etapa anterior que também pode ser desenvolvida pelos alunos.

3 - Observação do resultado da centrifugação. No fundo do tubo formou-se um precipitado escuro e a fase líquida agora tem um aspecto bem diferente. É necessário nesse momento explorar por meio de perguntas as ideias que os alunos apresentam para explicar o que aconteceu durante a centrifugação.

4 - Com uma pipeta Pasteur transfira o sobrenadante (toda parte líquida) para um novo tubo e reserve.

5 - No tubo que ficou com o precipitado, acrescente $1 \mathrm{~mL}$ de água e ressuspenda todo o material, agitando o tubo ou com o auxílio de uma pipeta. $O$ resultado desse procedimento (ressuspensão do precipitado) deve ser comparado com o tubo onde está o sobrenadante (Figura $2 \mathrm{~B}$ ).

Questionamentos: Nessa etapa também é importante que os alunos formulem hipóteses explicativas para o que está sendo observado. A interferência do professor pode ser necessária para, por meio de perguntas auxiliares, permitir que os alunos compreendam as diferenças entre os pigmentos. 


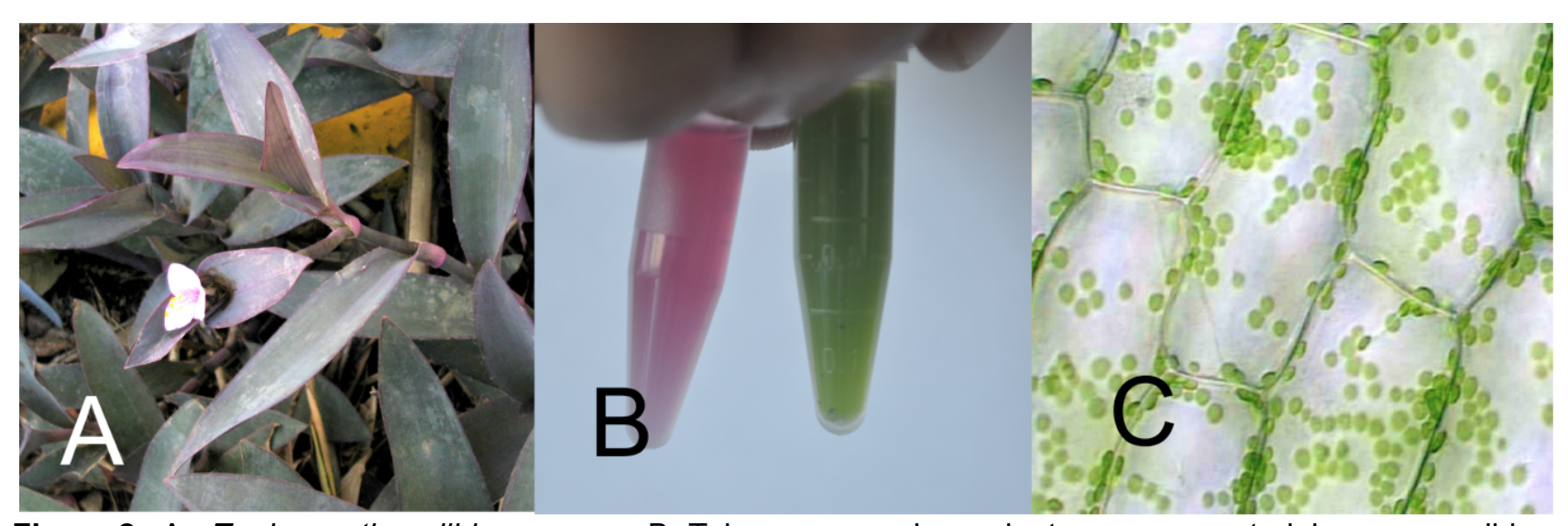

Figura 2. A- Tradescantia pallida purpurea; B- Tubos com o sobrenadante e com o material ressuspendido; C- Aspecto geral de célula vegetal com cloroplastos observada em microscópio óptico.

Explicando o observado:

A cor roxa da folha de Tradescantia é devido a um pigmento chamado antocianina que, por ser hidrossolúvel, fica dissolvido no sobrenadante. Isso explica porque o sobrenadante terá cor roxa, mesmo depois de vários minutos de centrifugação.

Uma célula vegetal típica possui núcleo com diâmetro em torno de 5 a $10 \mu \mathrm{M}$ e cloroplastos com 4 a $7 \mu \mathrm{M}$ [2]. Os cloroplastos, assim como o núcleo e algumas outras organelas, embora microscópicas, são estruturas suficientemente grandes (Figura $2 \mathrm{C}$ ) para precipitar por centrifugação e formar a massa que se deposita no fundo do tubo. Quando a massa depositada no fundo do tubo é ressuspendida, os cloroplastos ficarão suspensos, dando ao líquido cor verde (Figura 2 B). As outras organelas precipitadas são incolores.

\subsection{Experimento 2}

Nessa etapa será utilizado apenas o material ressuspendido que contém os cloroplastos.

1 - Em dois tubos de microcentrífuga coloque $0,5 \mathrm{~mL}$ do material ressuspendido.

2 - Em um dos tubos acrescente uma gota de detergente (identifique esse tubo com uma caneta permanente) e misture na solução, invertendo o tubo várias vezes.

Questionamentos: O que está acontecendo dentro do tubo? Qual será a ação do detergente sobre as membranas celulares? Essa etapa pode ser complementada, em planejamentos para atividades de duração mais longa, com observação do material em microscópio. 


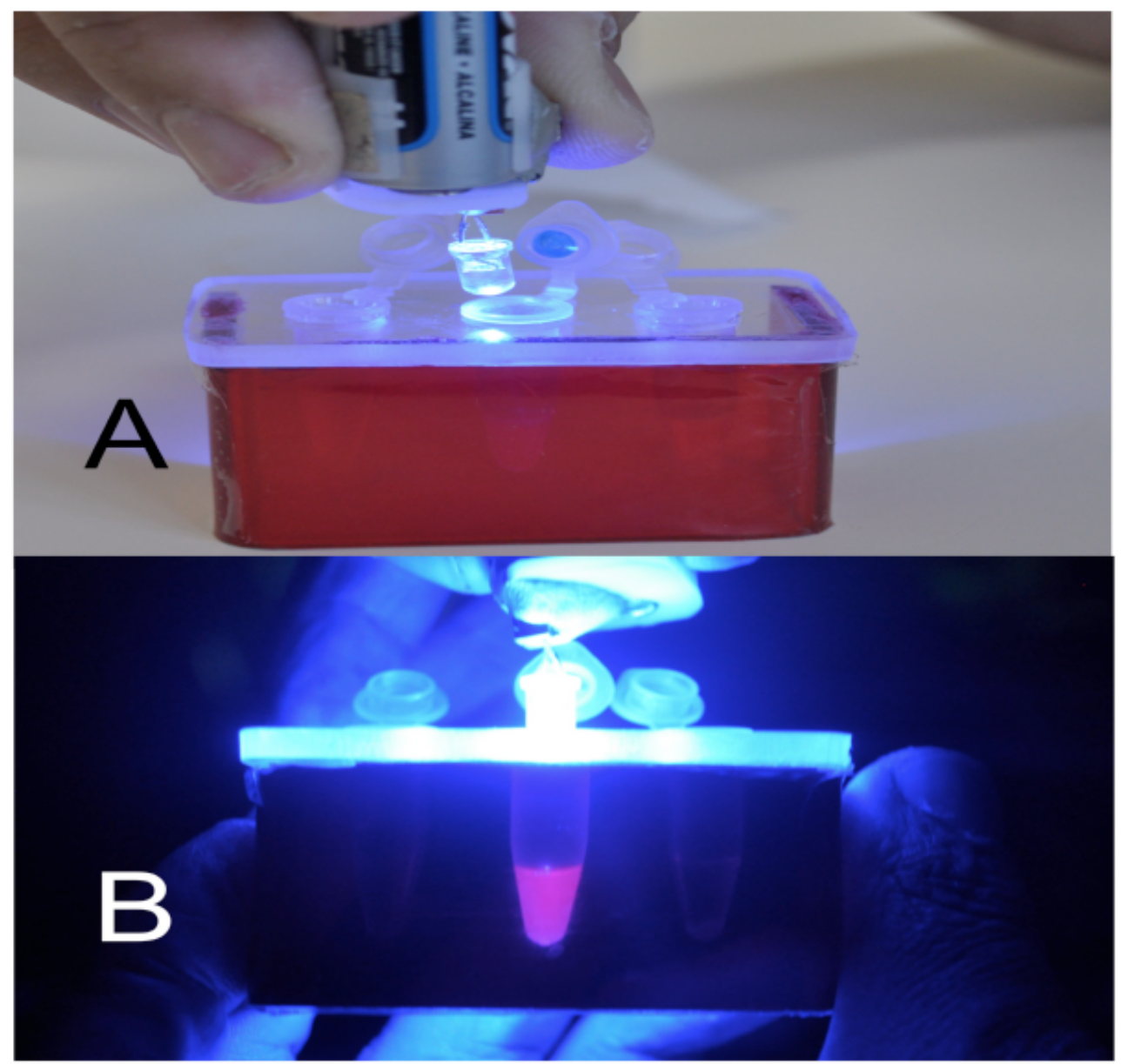

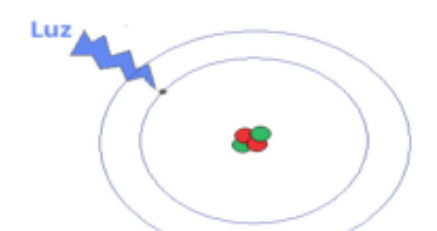

1

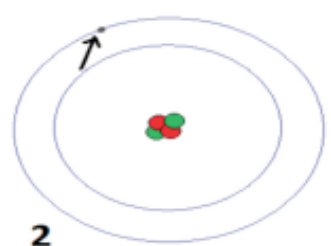

2

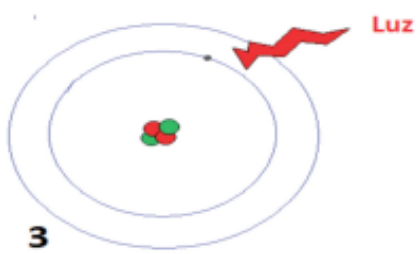

3

Figura 3. A - Caixa de acrílico vermelho com os tubos de microcentrífuga com as amostras; B Observação de amostra fluorescendo no escuro, iluminada com o LED azul; C) Esquema representando o fenômeno de fluorescência como resultado da excitação de um elétron que "salta" para um orbital de maior nível energético, quando este elétron volta ao seu orbital fundamental, ele libera a energia recebida na forma de luz.

3 - Coloque os dois tubos (com e sem detergente) abertos na cuba de acrílico vermelho. Em um ambiente com pouca iluminação, ilumine com o LED azul o líquido no interior do tubo com detergente, faça o mesmo com o outro tubo. A observação dos tubos deve ser feita através da caixa de acrílico, quanto mais escuro for o ambiente mais fácil será observar as diferenças.

Questionamentos: i) Por que um fluoresce e outro não? O tubo em que os cloroplasto 
foram desintegrados pelo detergente fluoresce em vermelho (Figura $3 \mathrm{~B}$ ). $\mathrm{O}$ tubo com os cloroplastos intactos não deve fluorescer ou, caso a intensidade do LED for grande, apresentará pouca fluorescência. Por que para visualizar a fluorescência colocamos os tubos em uma caixa de acrílico vermelho?

ii) Algumas questões podem ser desenvolvidas sob forma de experimentos adicionais: $A$ fluorescência poderia ser observada com outros tipos de LED? Somente a clorofila fluoresce ou a antocianina também tem essa propriedade? Podemos observar a fluorescência através de filtros de outra cor que não o vermelho?

\section{Explicando o observado}

O que é fluorescência? Por que a clorofila fluoresce?

Radiações eletromagnéticas são ondas que se propagam no espaço carregando pacotes de energia, chamados fótons (Figura $3 \mathrm{C}$ ). A luz é apenas uma pequena parte de todo o espectro das radiações eletromagnéticas.

A clorofila é uma molécula com a propriedade de fluorescência porque possui elétrons que podem receber energia da luz (fótons). Quando recebem fótons os elétrons passam a ocupar um orbital mais externo (de maior energia). No momento seguinte, o elétron será novamente atraído pelo núcleo do átomo. Mas para voltar ao seu orbital original, precisará liberar a energia recebida. É nesse momento que ocorre a fluorescência, o elétron libera a energia recebida emitindo luz e calor (Atkins e Paula, 2006). Geralmente a luz emitida é de um comprimento de onda diferente do recebido. A clorofila é excitada com luz azul e emite luz vermelha. Um filtro vermelho (neste caso o acrílico) permite que seja visualizado a fluorescência da clorofila (vermelho), permitindo que este comprimento de onda passe pelo filtro. A luz azul do LED, que ilumina igualmente os tubos com clorofila em solução, que fluoresce, e o tubo com os cloroplastos íntegros, que não fluoresce, será barrado pelo filtro, permitindo assim uma melhor visualização da fluorescência.

A molécula de clorofila, por ter uma região apolar, fica imersa dentro da camada lipídica da membrana dos cloroplastos. A clorofila também está associada a um sistema chamado "cadeia transportadora de elétrons" porque é capaz de captar os elétrons que "saltam" de um orbital para outro quando estão carregando "energia extra". Estes elétrons 
"ricos em energia" fluirão pela cadeia transportadora e serão usadas para síntese de moléculas ricas em energia (ATP e $\mathrm{NADPH}_{2}$ ). A energia captada pela clorofila será acumulada nessas moléculas e não será disponibilizada na forma de fluorescência (Figura $4 \mathrm{~A}, \mathrm{~B}$ ).

A clorofila precisa de reposição dos elétrons perdidos e novos elétrons são obtidos pela quebra da molécula de água. A água será quebrada em oxigênio (liberado na atmosfera, como produto da fotossíntese $-\mathrm{O}_{2}$ ) e o hidrogênio que será separado em elétron e próton. Estes serão usados para síntese de ATP. Os prótons e elétrons reduzirão a molécula de NADP em NADPH${ }_{2}$.

No tubo com adição de detergente ocorre a desintegração da bicamada lipídica da membrana do cloroplasto e essa organela é destruída. A clorofila que estava na membrana ficará nas micelas com o detergente, perdendo a associação com as proteínas e citocromos da cadeia transportadora de elétrons. Agora isolada, a clorofila, quando excitada pela luz, continuará tendo elétrons que saltam para orbitais de maior energia. Esses elétrons, ao retornarem aos seus orbitais originais liberam a energia recebida na forma de LUZ no comprimento de onda do VERMELHO (fluoresce vermelho).

Quando o cloroplasto está integro, o elétron na molécula de clorofila que "salta" do seu orbital, por receber energia da luz, é captado pela cadeia transportadora de elétrons e por isso não temos fluorescência. Quando usamos um LED que produz maior intensidade luminosa, podemos ver uma pequena fluorescência. A explicação para esse fenômeno é que a cadeia transportadora de elétrons não consegue transportar todos os elétrons excitados, quando a intensidade luminosa é muito intensa. Nos cloroplastos intactos, a energia captada pela clorofila acaba assim, em elétrons que ocupam níveis energéticos superiores nas moléculas de ATP e $\mathrm{NADPH}_{2}$.

Por meio de enzimas do Ciclo de Calvin, ou fase não luminosa da fotossíntese, que ocorre no estroma dos cloroplastos, a energia "transportada" pelas moléculas de ATP e $\mathrm{NADPH} \mathrm{H}_{2}$ será usada para formar ligações em moléculas pobres em energia $\left(\mathrm{CO}_{2}\right.$ e $\left.\mathrm{H}_{2} \mathrm{O}\right)$ e assim, formar uma nova molécula, a glicose, em que há ligações ricas em energia (Figura $4 \mathrm{C}$ ). Esta molécula doce vai ser o combustível na vida de plantas e animais. 


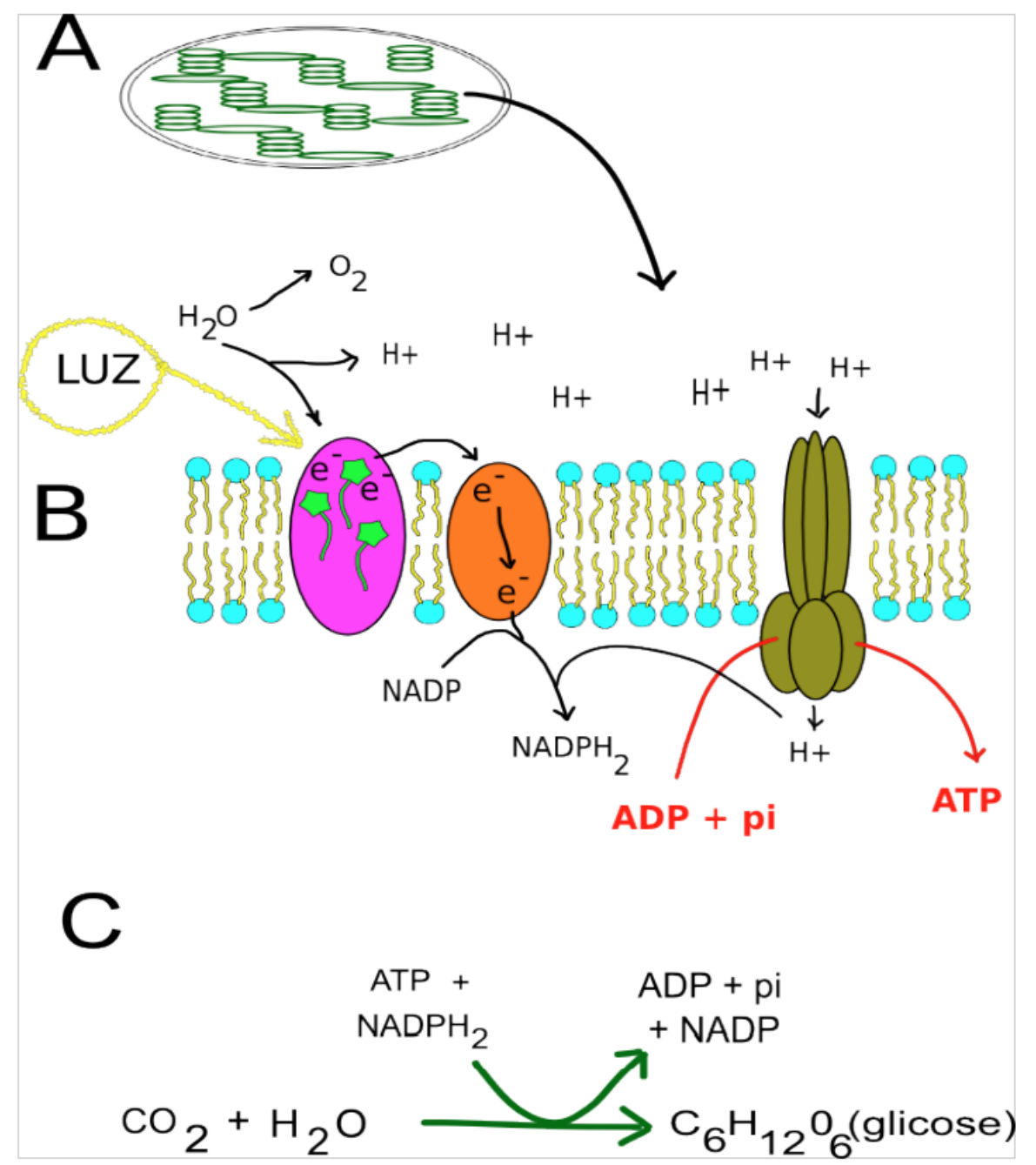

Figura 4. Esquema de um cloroplasto, representando no interior da organela "pilhas" de pequenos sacos membranosos (tilacoides). Na membrana destes tilacoides (B) existem complexos protéicos nos quais as moléculas de clorofila (em verde) estão imersas. A luz, ao interagir com a clorofila faz com que elétrons "saltem" desta molécula. Estes elétrons serão capturados pela cadeia transportadora de elétrons (representado pela elipse laranja). A clorofila obterá um novo elétron do hidrogênio da molécula de água. A retirada dos hidrogênios de duas moléculas de água para repor os elétrons da clorofila, liberará $\mathrm{O}_{2}$ (produto da fotossíntese). Os elétrons que fluem pela cadeia transportadora de elétrons reduzirão o cofator NADP para $\mathrm{NADPH}_{2}$. Os prótons do hidrogênio formarão um gradiente dos dois lados da membrana, e o fluxo destes prótons por meio da enzima ATP sintetase permite a síntese de ATP a partir de ADP e fosfato inorgânico (Pi). C) No interior do cloroplasto (estroma), utilizando a energia acumulada no $\mathrm{NADPH}_{2}$ e ATP, ocorrerá um conjunto de reações (Ciclo de Calvin) que empregará $\mathrm{CO}_{2}$ e $\mathrm{H}_{2} \mathrm{O}$ para sintetizar uma molécula rica em energia, a glicose [2]. 


\section{Referências}

[1] Lavaqui V, Batista IL. Interdisciplinaridade em ensino de Ciências e Matemática no Ensino Médio. Ciência \& Educação 2007; 13 (3): 399 - 420. www.scielo.br/pdf/ciedu/v13n3/a09v13n3.pdf

[2] Alberts B, Johnson A, Lewis J, Raff M, Walter P. Biologia Molecular da Célula, 5. ed, Porto Alegre: ArtMed; 2009.

Atkins P, Paula J. Physical Chemistry. 8. ed. Oxford: Oxford University Press, 2006.

[3] Sepel LMN, Loreto ELS. Isolation and Visualization of Nucleic Acid with Homemade Apparatus. Bioch. and Mol. Biol. Education 2002; 30(5):306-308.

DOI: 10.1002/bmb.2002.494030050122

[4] Sartori PHS, Loreto ELS. Medidor de fluorescência caseiro. Química Nova na Escola 2009; 31(2): 150-154. http://qnesc.sbq.org.br/online/qnesc31_2/13-EEQ-4508.pdf 